Benjamin Greiner*, DO, MPH, Jake Checketts, DO, Keith Fishbeck, DO and Micah Hartwell, PhD

\title{
Clinical characteristics and lifestyle behaviors among individuals with arthritis: an analysis of 2017 Behavioral Risk Factor Surveillance System data
}

https://doi.org/10.1515/jom-2020-0123

Received May 19, 2020; accepted July 23, 2020;

published online January 29, 2021

\section{Abstract}

Context: The combination of osteoarthritis and rheumatoid arthritis affects nearly one-fourth of Americans. Many of the risk factors for arthritis are lifestyle related, such as obesity, physical activity, dietary behaviors, and alcohol and tobacco use.

Objective: To analyze lifestyle behaviors of patients with vs. those without arthritis.

Methods: A cross-sectional analysis of 2017 Behavioral Risk Factor Surveillance System (BRFSS) data was conducted on patients with and without a history of arthritis. Physical activity, smoking status, alcohol use, and dietary behaviors were extracted. Logistic regression models were constructed to calculate adjusted risk ratios (ARRs). All confidence intervals (CIs) were reported at 95\%.

Results: The median response rate for the 2017 BRFSS survey was $45.1 \%$ (sample $n=292,808$; population $\mathrm{N}=118,751,156$ ). The overall prevalence of arthritis was $44 \%(n=128,850)$. Respondents with arthritis were significantly more likely to be physically inactive than nonarthritic respondents, with a significant gender interaction (male absolute risk reduction [ARR], 1.2 [CI, 1.15-1.25]; female ARR, 1.29 [CI, 1.24-1.33]). Those

*Corresponding author: Benjamin Greiner, DO, MPH, Department of Internal Medicine, University of Texas Medical Branch, 301 University Blvd, Galveston, TX 77555-5302, USA,

E-mail: ben.greiner10@gmail.com. https://orcid.org/0000-0001. 7604-2539

Jake Checketts, DO and Keith Fishbeck, DO, Department of Orthopedic Surgery, Oklahoma State University Medical Center, Tulsa, OK, USA

Micah Hartwell, PhD, Department of Psychiatry and Behavioral Sciences, Oklahoma State University Center for Health Sciences, Tulsa, OK, USA with arthritis were also more likely to be current smokers (ARR 1.1; CI, 1.05-1.15) and less likely to have attempted to quit smoking in the last 12 months (ARR, 0.91; CI, 0.87-0.96). Finally, men with arthritis were more likely to drink alcohol heavily (ARR, 1.14; CI, 1.02-1.27]).

Conclusion: Patients with arthritis were more likely to be women, White, current smokers, and physically inactive, and to have poor mental health, lower education levels, and difficulty paying for healthcare and medications than those without arthritis. Further efforts should be made to address these findings through resource allocation in the care of patients with arthritis. Practitioners should also seek increased understanding of the psychological, social, and economic impacts of physical activity and smoking in patients with arthritis.

Keywords: arthritis; health promotion; lifestyle behaviors; patient-centered medicine.

Arthritis (in this study referring to all forms of arthritis unless specified otherwise) can be caused by varying disease processes, but each ultimately leads to painful inflammation, stiffness, and possibly destruction of the joint surface. Recent estimates by the Centers for Disease Control and Prevention (CDC) ${ }^{1}$ indicate that 23\% of Americans, or more than 54 million adults, live with arthritis, and that the annual direct medical costs attributable to arthritis exceeds $\$ 140$ billion. Furthermore, the global burden of hip and knee osteoarthritis is the 11th highest contributor to disability, ${ }^{2}$ and rheumatoid arthritis is also a major public health challenge. ${ }^{3}$ However, many of the risk factors for the development of rheumatoid arthritis are modifiable.

These risk factors for arthritis include obesity, tobacco use, hormone imbalances, high-impact occupations, autoimmune conditions, diabetes, and age..$^{4-6}$ Many of these comorbidities increase the odds of developing arthritis. ${ }^{7}$ 
Although the use of cigarettes by Americans has decreased in recent years, physical activity levels and diet quality remain suboptimal. ${ }^{8-10}$ Because these modifiable lifestyle factors play a large role in the development of arthritis, furthering the knowledge about lifestyle factors contributing to and worsening these debilitating conditions is very important for making advances in treatment and management. A clinical model should incorporate behavioral health, preventive medicine, and restoration of health, which is embedded within the osteopathic models.

Many studies have evaluated risk factors contributing to the disease process of arthritis. However, to our knowledge, no recent studies have analyzed the lifestyle behaviors of those diagnosed vs. those not diagnosed with arthritis using a nationally representative sample, such as the Behavioral Risk Factor Surveillance System (BRFSS), which is a CDC-managed, self-reported, previously validated, nationally representative database collecting lifestyle behavior and chronic disease information. Therefore, the primary objective of this study was to describe and analyze the sociodemographics and lifestyle behaviors of those diagnosed with vs. without arthritis using the BRFSS. The secondary objective was to determine which sociodemographics and lifestyle behaviors need further attention after a diagnosis of arthritis.

\section{Methods}

We conducted a cross-sectional analysis of lifestyle behaviors and clinical characteristics in Americans with and without a history of arthritis. Data were extracted from the 2017 BRFSS, which incorporated our variables of interest. In fulfillment of the appropriate reporting of recommended observational studies, this study was based on the Strengthening the Reporting of Observational Studies in Epidemiology (STROBE) guidelines. All data included in this study were publicly available and contained no protected health information with patient identifiers; therefore, this study did not require IRB submission or approval.

The BRFSS collects data from all 50 states, the District of Columbia, Puerto Rico, and Guam and includes all noninstitutionalized individuals or those in the military over age 18 years. Random sampling collapsed all available telephone numbers into two strata based on area code and density of population in the area code, followed by computer automated sampling. The data we extracted included sociodemographics, policy-level variables, and lifestyle behaviors including smoking status, alcohol use, physical activity, and diet. Respondents were classified as having arthritis if they responded "yes" to the question: "Has a doctor, nurse, or healthcare professional ever diagnosed you as having some form of arthritis?" All respondents answering "no" were classified as having no history of arthritis. Participants aged 18-44 years were excluded from analysis due to the low prevalence of autoimmune and nonautoimmune arthritis in this age group.

Statistical analysis was performed on March 3, 2020 using Stata 16.1. Sampling weights were obtained from BRFSS and used to calculate the estimated population size and 95\% confidence interval (CI). BRFSS utilizes an iterative proportional fitting method in determining the appropriate weights. We then computed descriptive statistics to describe sociodemographics, lifestyle behaviors, and policy-level variables. To determine independent risk factors for arthritis, we constructed a multivariate logistic regression model to calculate adjusted risk ratios (ARRs) by incorporating lifestyle behavior variables including smoking status, attempts to quit smoking, binge and heavy alcohol use, physical activity, and fruit/ vegetable consumption. ARRs were adjusted using age, gender, race, education, and healthcare coverage.

\section{Results}

\section{Sociodemographics}

The median response rate for the entire 2017 BRFSS survey was 45.1\% (sample $n=447,222$; population $N=254,205,400$ ). For the remainder of the manuscript, $\mathrm{n}$ indicates sample size and $\mathrm{N}$ indicates estimated population size. After excluding respondents who did not provide a response to the question regarding the presence of arthritis as well as respondents under age 45 , the remaining sample size was $292,808(N=118,751,156$; a population estimate based on the sample meeting inclusion criteria). Of all patients who reported a history of arthritis ( $\mathrm{n}=147,288)$, the prevalence of respondents over 45 years of age was $87 \%(128,850$ of $147,288)$. Those reporting a history of arthritis were predominantly elderly, with the majority being age 55 to 64 $(39,620 ; 26.9 \%)$, female $(88,019 ; 59.76 \%)$, and White, non-Hispanic $(107,490 ; 72.98 \%$; Table 1). Respondents with arthritis were more likely to have healthcare coverage (95.27\% of those with arthritis vs. $92.33 \%$ of those without), to have a BMI greater than $25 \mathrm{~kg} / \mathrm{m}^{2}(74.83 \%$ of those with arthritis vs. $66.84 \%$ of those without), and to be high school than college graduates $(30.21 \%$ of those with arthritis vs. $21.56 \%$ of those without). Finally, participants reporting greater than 14 poor mental health days per month were significantly more likely to have a history of arthritis 
Table 1: Sociodemographic factors in patients with a history of arthritis and no history of arthritis $(n=447,222 ; N=254,205,400)$.

\begin{tabular}{|c|c|c|c|}
\hline & & $\begin{array}{r}\text { No arthritis } n=299,934 ; \\
\mathrm{N}=191,829,047(95 \% \mathrm{Cl})\end{array}$ & $\begin{array}{r}\text { With arthritis }{ }^{a} n=147,288 \\
N=62,376,353(95 \% \mathrm{Cl})\end{array}$ \\
\hline \multirow[t]{7}{*}{ Age, years } & $18-24$ & $26.49(26.11-26.88)$ & $3.40(3.17-3.64)$ \\
\hline & $25-34$ & $21.17(20.84-21.5)$ & $6.75(6.42-7.09)$ \\
\hline & $35-44$ & $16.77(16.48-17.07)$ & $11.50(11.10-11.92)$ \\
\hline & $45-54$ & $15.55(15.28-15.82)$ & $22.00(21.51-22.50)$ \\
\hline & $55-64$ & $11.22(11.01-11.44)$ & $26.90(26.40-27.41)$ \\
\hline & $65-74$ & $6.011(5.853-6.173)$ & $19.71(19.27-20.16)$ \\
\hline & $75+$ & $2.784(2.675-2.897)$ & $9.74(9.41-10.08)$ \\
\hline \multirow[t]{2}{*}{ Gender } & Female & $48.63(48.24-49.02)$ & $59.76(59.19-60.33)$ \\
\hline & Male & $51.37(50.98-51.76)$ & $40.24(39.67-40.81)$ \\
\hline \multirow[t]{8}{*}{ Race/ethnicity } & White, non-Hispanic & $59.28(58.87-59.69)$ & $72.98(72.36-73.58)$ \\
\hline & Black, non-Hispanic & $11.78(11.53-12.03)$ & $11.91(11.48-12.36)$ \\
\hline & Hispanic & $0.92(0.8634-0.9746)$ & $1.27(1.16-1.40)$ \\
\hline & American Indian/Alaskan Native & $6.51(6.24-6.79)$ & $2.10(1.81-2.40)$ \\
\hline & Asian, non-Hispanic & $0.23(0.2056-0.266)$ & $0.13(0.11-0.17)$ \\
\hline & Native Hawaiian/Pacific Islander & $0.45(0.4059-0.4975)$ & $0.44(0.37-0.53)$ \\
\hline & Other race, non-Hispanic & $1.38(1.31-1.45)$ & $1.51(1.40-1.62)$ \\
\hline & Multiracial, non-Hispanic & $19.45(19.09-19.82)$ & $9.66(9.23-10.10)$ \\
\hline \multicolumn{2}{|l|}{ Over 45 years of age } & $n=163,958 ; N=69,715,955$ & $n=128,850 ; N=49,035,201$ \\
\hline \multirow[t]{2}{*}{ Healthcare coverage } & Yes & $92.33(91.98-92.66)$ & $95.27(94.97-95.56)$ \\
\hline & No & $7.67(7.34-8.02)$ & $4.73(4.44-5.03)$ \\
\hline \multirow[t]{4}{*}{ Education } & Did not graduate high school & $12.86(12.41-13.32)$ & $16.24(15.70-16.80)$ \\
\hline & High school graduate & $27.53(27.03-28.02)$ & $30.21(29.65-30.78)$ \\
\hline & Attended college but did not graduate & $28.90(28.38-29.44)$ & $31.98(31.38-32.59)$ \\
\hline & College or technical school graduate & $30.71(30.23-31.18)$ & $21.56(21.12-22.02)$ \\
\hline \multirow[t]{2}{*}{ BMI greater than 25} & Yes & $66.84(66.29-67.40)$ & $74.83(74.26-75.40)$ \\
\hline & No & $33.16(32.60-33.71)$ & $25.17(24.60-25.74)$ \\
\hline \multirow[t]{2}{*}{ Veteran } & Yes & $14.59(14.23-14.95)$ & $15.70(15.25-16.16)$ \\
\hline & No & $85.41(85.05-85.77)$ & $84.30(83.84-84.75)$ \\
\hline \multirow[t]{3}{*}{ Poor mental health } & 0 day & $77.95(77.49-78.41)$ & $63.96(63.34-64.58)$ \\
\hline & $1-13$ days & $15.19(14.80-15.59)$ & $20.14(19.63-20.65)$ \\
\hline & $14+$ days & $6.85(6.58-7.14)$ & $15.90(15.42-16.40)$ \\
\hline
\end{tabular}

${ }^{a}$ Patients with arthritis represented a sample size $n=147,288$ and population estimate $N=62,376,353$. Likewise, patients with arthritis who were also over age 45 years had a sample size of $n=128,850$, which represented a population estimate of $N=49,035,201$. BMI, body mass index; $\mathrm{Cl}$, confidence interval.

(15.90\%; CI, 15.42-16.40) compared to those with no arthritis history $(6.85 \%$; CI, 6.58-7.14).

\section{Work and activity limitations}

Considering respondents with a history of arthritis, the following work and activity data were obtained. Approximately $79 \%$ of respondents $(102,268)$ reported that arthritis prevents them from doing everything they want, and 51\% $(66,022)$ reported that arthritis prevents them from doing their usual activities. Over 33\% $(43,138)$ reported that arthritis limits the type or amount of work they can perform. Finally, 48\% $(61,332)$ reported that arthritis limits their social activities (Table 2). On a scale of $0-10$, the mean amount of joint pain over the past 30 days was 4.74 (SD, 2.84).

\section{Policy-level factors}

Of respondents with a history of arthritis, only $12.76 \%$ $(16,441)$ reported having taken a class on managing arthritis symptoms (Table 2). Among participants with a history of arthritis and a BMI over $25 \mathrm{~kg} / \mathrm{m}^{2}, 47.28 \%$ $(60,920)$ reported having a doctor suggest weight loss as a viable option for managing arthritis. Among respondents with arthritis and physical inactivity, 55.25\% (71,189) reported having a doctor suggest the use of physical activity. In contrast, among those reporting a history of arthritis and 
Table 2: Prevalence of limited or reduced social and work activity and policy level healthcare factors among individuals with and without arthritis 45 years of age and older $(n=292,808 ; N=118,751,156)$.

\begin{tabular}{|c|c|c|}
\hline & $\begin{array}{r}\text { No arthritis } \mathrm{n}=163,958 \\
\mathrm{~N}=69,715,955 \%^{\mathrm{c}}(95 \% \mathrm{Cl})\end{array}$ & $\begin{array}{l}\text { With arthritis } \mathrm{n}=128,850 \text {, } \\
\mathrm{N}=49,035,201 \%^{\mathrm{c}}(95 \% \mathrm{Cl})\end{array}$ \\
\hline Unable to afford doctor visit & $8.39(8.07-8.73)^{b}$ & $11.87(11.43-12.31)^{\mathrm{b}}$ \\
\hline Unable to afford medications $^{d}$ & $6.26(5.43-7.21)^{\mathrm{b}}$ & $11.97(10.77-13.28)^{\mathrm{b}}$ \\
\hline Have unpaid health bills ${ }^{e}$ & $14.73(13.60-15.94)^{b}$ & $19.98(18.50-21.54)^{\mathrm{b}}$ \\
\hline Had doctor visit within previous year & $77.48(77.00-77.96)^{\mathrm{b}}$ & $84.96(84.48-85.43)^{\mathrm{b}}$ \\
\hline Screened for alcohol use during last checkup ${ }^{f}$ & $73.77(72.15-75.32)$ & $72.97(71.26-74.62)$ \\
\hline \multicolumn{2}{|c|}{ Do arthritis or joint symptoms limit or prevent any of your usual activities? ${ }^{a}$} & $51.24(50.60-51.88)$ \\
\hline \multicolumn{2}{|c|}{ Do arthritis or joint symptoms limits your work (type or amount)? ${ }^{\mathrm{ag}}$} & $33.48(32.89-34.08)$ \\
\hline \multicolumn{2}{|c|}{$\begin{array}{l}\text { Do arthritis or joint symptoms limits your social activities, such as going shopping, to the } \\
\text { movies, or to religious or social gatherings? }\end{array}$} & $47.6(46.97-48.24)$ \\
\hline \multicolumn{2}{|c|}{ Do arthritis or joint symptoms prevent you from doing everything you want? ${ }^{\mathrm{ai}}$} & $79.37(77.89-80.79)$ \\
\hline \multicolumn{2}{|l|}{ Average joint pain $(0-10)$ over past 30 days $M(\mathrm{SD})^{\mathrm{a}}$} & $4.74(2.84)$ \\
\hline \multicolumn{2}{|l|}{ Ever taken class in managing arthritis? ${ }^{\mathrm{aj}}$} & $12.76(11.61-14.00)$ \\
\hline \multicolumn{3}{|c|}{ Has a doctor suggested losing weight to help your arthritis or joint symptoms? $?^{\mathrm{ak}}$} \\
\hline \multicolumn{2}{|l|}{ Among >25 BMI } & $47.28(44.92-49.65)$ \\
\hline \multicolumn{2}{|l|}{ Among <25 BMI } & $6.29(4.73-8.32)$ \\
\hline \multicolumn{3}{|c|}{ Has a doctor suggested physical activity to help your arthritis or joint symptoms? $?^{\text {al }}$} \\
\hline \multicolumn{2}{|l|}{ Among those who are sedentary } & $55.25(51.79-58.66)$ \\
\hline \multicolumn{2}{|c|}{ Among those meeting exercise guidelines ( 150 min per week) } & $59.58(56.90-62.21)$ \\
\hline
\end{tabular}

physical activity, only 59.58\% (76,768) stated that they achieve 150 min of physical activity weekly.

Participants with vs. without a history of arthritis were significantly more likely to be unable to afford doctor visits and medications $(15,294$ [11.87\%] vs. 13,756 [8.39\%]; $\mathrm{p}<0.05$; Table 2). Among respondents with an arthritis history, approximately 20\% $(25,744)$ reported having an unpaid health bill compared to $14.73 \%(24,151)$ of those without arthritis. Finally, respondents with arthritis were more likely to have had a doctor visit within the last year than those who had not $(109,470$ [84.96\%] vs. 127,034 [77.48\%]; $p<0.05)$. No statistically significant difference existed among respondents reporting being screened for alcohol use at the last checkup.

\section{Lifestyle behaviors}

The prevalence of respondents with arthritis who were current smokers was significantly higher than those without arthritis (ARR, 1.10; CI, 1.05-1.15), as shown in Tables 3 and 4. Those with arthritis were also less likely to report an attempt to quit smoking in the previous 12 months (ARR, 0.91; CI, 0.87-0.96). In the analysis of binge drinking, respondents with arthritis were significantly less likely to binge drink $(10,865,8.43 \%$; CI, 8.06-8.82) than the non-arthritis sample $(17,379,10.6 \%$; CI, 10.24-10.97). After adjustments were applied, a gender interaction existed in the calculated ARR. The ARR in women who binge drink was 0.88 (CI, 0.8-0.97; p<0.05), although statistical significance was not achieved in men (ARR, 1.032; CI, 0.96-1.11). The difference of prevalence in arthritic patients reporting heavy alcohol use was statistically significant compared to the nonarthritic cohort. The ARR in men who heavily drink was 1.14 (CI, 1.02-1.27) and in women was 0.86 (CI, 0.78-0.95).

Finally, physical activity and diet behaviors were analyzed. Respondents with arthritis were more likely to be physically inactive ( $\mathrm{n}=47,300,36.71 \%$; $\mathrm{CI}, 36.07-37.34)$ than those without arthritis ( $\mathrm{n}=43,268,26.39 \%$; CI, 25.88-26.92). Considering gender interactions, physically inactive men had an ARR of 1.2 (CI, 1.15-1.25), whereas physically inactive women had an ARR of 1.29 (CI, 1.24-1.33). Respondents with arthritis were more likely to not meet the recommended intake guidelines for fruits and vegetables (5+ servings per 
Table 3: Prevalence of lifestyle behaviors among individuals with and without arthritis 45 years of age and older $(n=292,808$; $\mathrm{N}=118,751,156)$.

\begin{tabular}{|c|c|c|}
\hline & $\begin{array}{r}\text { No arthritis } \\
n=163,958, \\
\mathrm{~N}=69,715,955 \% \\
(95 \% \mathrm{Cl})\end{array}$ & $\begin{array}{r}\text { With arthritis } \\
n=128,850, \\
N=49,035,201 \% \\
(95 \% \mathrm{Cl})\end{array}$ \\
\hline urrent smoker & $\begin{array}{r}13.29(12.90- \\
13.69)^{\mathrm{a}}\end{array}$ & $\begin{array}{r}15.30(14.85- \\
15.77)^{\mathrm{a}}\end{array}$ \\
\hline $\begin{array}{l}\text { Smoking quit attempt } \\
\text { in past } 12 \text { months }\end{array}$ & $\begin{array}{r}46.80(45.29- \\
48.32)^{\mathrm{a}}\end{array}$ & $\begin{array}{r}41.91(40.35- \\
43.49)^{\mathrm{a}}\end{array}$ \\
\hline $\begin{array}{l}\text { Binge drinking (men } \\
\text { having } 5+\text { drinks and } \\
\text { women having } 4+\text { drinks } \\
\text { on one occasion) }\end{array}$ & $\begin{array}{r}10.60(10.24- \\
10.97)^{\mathrm{a}}\end{array}$ & $8.433(8.06-8.82)^{a}$ \\
\hline $\begin{array}{l}\text { Heavy drinking (men } \\
\text { having }>14 \text { drinks and } \\
\text { women having }>7 \text { drinks } \\
\text { per week) }\end{array}$ & $5.56(5.31-5.83)$ & $5.16(4.88-5.45)$ \\
\hline No physical activity & $\begin{array}{r}26.39(25.88- \\
26.92)^{\mathrm{a}}\end{array}$ & $\begin{array}{r}36.71(36.07- \\
37.34)^{\mathrm{a}}\end{array}$ \\
\hline $\begin{array}{l}<5 \text { daily servings of } \\
\text { fruit/vegetables }\end{array}$ & $\begin{array}{r}71.27(70.75- \\
71.79)^{\mathrm{a}}\end{array}$ & $\begin{array}{r}73.86(73.29- \\
74.41)^{\mathrm{a}}\end{array}$ \\
\hline $\begin{array}{l}\text { Consumes sugar- } \\
\text { sweetened beverage }\end{array}$ & $\begin{array}{r}96.97 \text { (96.84- } \\
97.09)\end{array}$ & $96.9(96.75-97.04)$ \\
\hline
\end{tabular}

${ }^{\text {a }}$ Statistically significant differences between persons with and without arthritis. $\mathrm{Cl}$, confidence interval.

day) compared to those without arthritis (ARR, 1.15; CI, $1.10-1.20$ ). No statistically significant difference existed between arthritic and nonarthritic respondents regarding the consumption of sugar-sweetened beverages.

\section{Discussion}

Our study found that patients with arthritis were significantly less likely to be physically active than those without arthritis. Furthermore, our data also demonstrated that those living with arthritis were less likely to be able to do the preferred activities, type and amount of work, and social activities that could be performed. These findings are concerning because participating in joint-friendly physical activity can improve pain, function, quality of life, and even mental health in those living with arthritis. ${ }^{11,12}$ Likewise, when a patient's work and social life are inhibited, his or her morale may also be affected. Additionally, the present study identified that arthritic patients were more likely to report an increased number of poor mental health days, which has been shown to worsen the self-management of arthritis. ${ }^{13,14}$ Other contributors to the association between poor mental health days and
Table 4: Adjusted risk ratios of lifestyle behaviors among individuals 45 years of age and older with arthritis, compared to those without arthritis $(n=292,808 ; N=118,751,156)$.

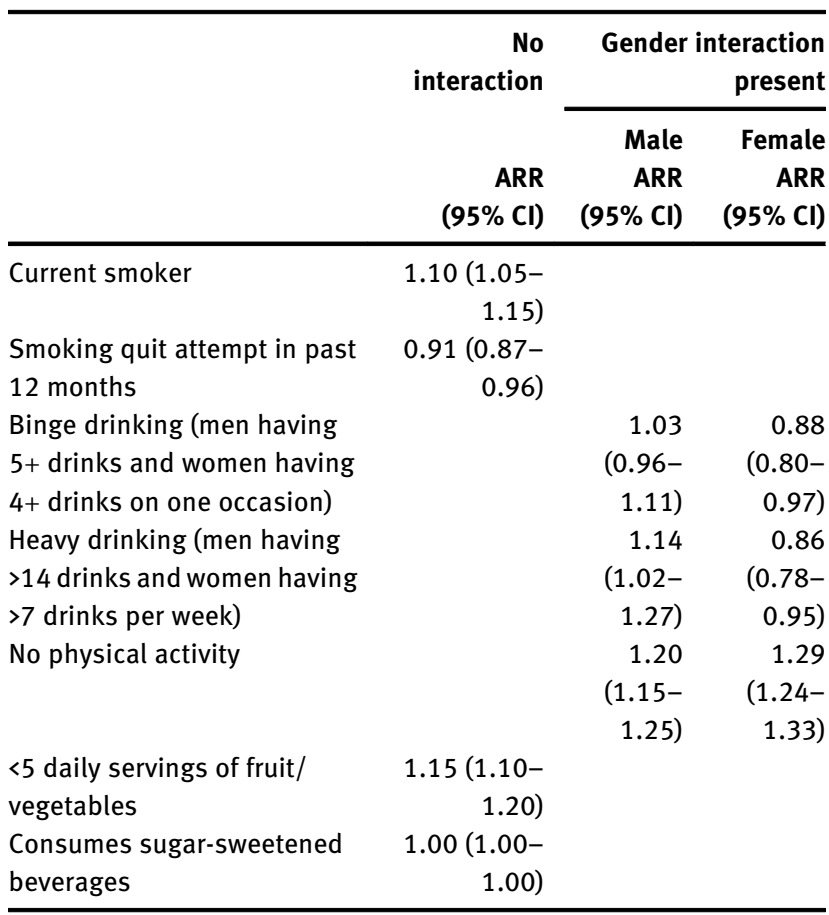

$\mathrm{ARR}$, adjusted risk ratio; $\mathrm{Cl}$, confidence interval.

arthritis include biochemical and genetic factors, which should also be considered in the management of arthritis. ${ }^{15,16}$ Finally, because our study found that those diagnosed with arthritis were more likely to have unpaid medical bills and were less likely to be able to afford medications than those without a diagnosis, financial strain is likely contributing to the poor mental health days reported by this patient population. Thus, it is important to bring the mental health aspects of these conditions to light to provide patient-centered care in the management of arthritis.

A further concern elucidated in our study is that those diagnosed with arthritis were more likely to be current smokers than those who were not diagnosed. Although this is predictable because smoking has been identified as a risk factor for arthritis, ${ }^{3-7}$ the prevalence of smoking continuation should be of concern to those providing care to these patients. Unfortunately, in addition to the additive effects of smoking and arthritis, current evidence also suggests that the effects of biologics used in the treatment of some arthritis may be diminished in heavy smokers. ${ }^{17}$ Thus, the importance of quitting smoking should be emphasized to manage arthritis.

The findings of our research were supported by several other studies. First, physical inactivity was widespread 
among patients with arthritis in previous BRFSS database years as well as among patients in other large databases, and this continues to be an issue, as the present study shows. ${ }^{18,19}$ Furthermore, in prospective studies and clinical trials, physical inactivity has been confirmed as a risk factor for arthritis. ${ }^{20,21}$ Additionally, a meta-analysis of observational studies identified smoking as a strong risk factor for the development of seropositive rheumatoid arthritis, ${ }^{22}$ and another report has also noted that patients with arthritis are more likely to be depressed or to report poor mental health days, both of which are supported by this study. ${ }^{23}$ These studies, among other current research, indicate that the findings of the present study are in alignment and directly supported by the current knowledge of arthritis and its associated risk factors.

Our study identified alcohol abuse patterns that differed from other studies. The 2011-2014 National Health and Nutrition Examination Survey (NHANES) study found that, among 4,792 patients with arthritis, 15.6\% (749) reported recent binge drinking behaviors, compared to $8 \%$ $(10,865)$ in our sample. ${ }^{24}$ Another study found that $6 \%$ of binge drinkers reported a history of arthritis. ${ }^{25}$ However, variations in arthritis survey questions between these studies may be an explanation for the differences. These variations may have been due to sampling differences or response bias, although the lack of current research into how binge and heavy drinking impact arthritis is an area in which clarity is needed. The lack of research is particularly concerning due to our findings that men with arthritis were significantly more likely to report heavy drinking compared to their nonarthritic cohorts.

This study had several limitations and some strengths. First, the study design was cross-sectional; thus, causation claims could not be made. Second, measured variables were self-reported, which may have imputed response bias into our analyses because respondents may have reported false statements. Finally, the median response rate for the entire 2017 BRFSS survey was 45.1\%, which may have limited the generalizability of the findings. The strengths of this study included its large sample size and the thoroughness of the sampling techniques.

\section{Conclusion}

The present study identified several behaviors and policylevel factors associated with patients diagnosed with arthritis. Notably, those diagnosed with arthritis were more likely to be women, White, above the ideal body weight, and to have the following characteristics: physical inactivity, tobacco use, poor mental health, lower education levels, difficulty paying for healthcare and medications, and men were more likely to drink heavily. This population was less likely to have attempts to quit smoking. These findings offer new areas on which clinicians should focus and better allocate resources in the care of patients with arthritis. Further research should be made to address these findings and should be applied to finding methods for improving physical activity and smoking cessation, as well as improving the understanding of the psychological, social, and economic impacts of physical activity and smoking, in patients with arthritis.

Research funding: None reported.

Author contributions: Drs. Greiner and Hartwell provided substantial contributions to conception and design, acquisition of data, or analysis and interpretation of data; Drs. Greiner, Checketts, Fishbeck, and Hartwell drafted the article or revised it critically for important intellectual content; Dr. Hartwell gave final approval of the version of the article to be published; and all authors agree to be accountable for all aspects of the work in ensuring that questions related to the accuracy or integrity of any part of the work are appropriately investigated and resolved.

Competing interests: Authors state no conflict of interest. Support: None reported.

\section{References}

1. Guglielmo D, Murphy LB, Boring MA, et al. State-specific severe joint pain and physical inactivity among adults with arthritis United States, 2017. MMWR Morb Mortal Wkly Rep. 2019;68(17): 381-387. doi: 10.15585/mmwr.mm6817a2.

2. Cross M, Smith E, Hoy D, et al. The global burden of hip and knee osteoarthritis: estimates from the Global Burden of Disease 2010 study. Ann Rheum Dis. 2014;73(7):1323-1330. doi: 10.1136/ annrheumdis-2013-204763.

3. Safiri S, Kolahi AA, Hoy D, et al. Global, regional and national burden of rheumatoid arthritis 1990-2017: a systematic analysis of the Global Burden of Disease study 2017. Ann Rheum Dis. 2019;78(11):1463-1471. doi: 10.1136/annrheumdis-2019-215920.

4. van der Woude D, van der Helm-van Mil AHM. Update on the epidemiology, risk factors, and disease outcomes of rheumatoid arthritis. Best Pract Res Clin Rheumatol. 2018;32(2):174-187. doi: 10.1016/j.berh.2018.10.005.

5. Solmaz D, Eder L, Aydin SZ. Update on the epidemiology, risk factors, and disease outcomes of psoriatic arthritis. Best Pract Res Clin Rheumatol. 2018;32(2):295-311. doi: 10.1016/j.berh.2018.09.006.

6. O'Neill TW, McCabe PS, McBeth J. Update on the epidemiology, risk factors and disease outcomes of osteoarthritis. Best Pract Res Clin Rheumatol. 2018;32(2):312-326. doi: 10.1016/j.berh.2018.10.007.

7. Blagojevic M, Jinks C, Jeffery A, Jordan KP. Risk factors for onset of osteoarthritis of the knee in older adults: a systematic review and meta-analysis. Osteoarthr Cartil. 2010;18(1):24-33. doi: 10.1016/j. joca.2009.08.010. 
8. Wilson MM, Reedy J, Krebs-Smith SM. American diet quality: where it is, where it is heading, and what it could be. J Acad Nutr Diet. 2016;116(2):302-310.e1. doi: 10.1016/j.jand.2015.09.020.

9. Church TS, Thomas DM, Tudor-Locke C, et al. Trends over 5 decades in U.S. occupation-related physical activity and their associations with obesity. PLoS One. 2011;6(5):e19657. doi: 10. 1371/journal.pone.0019657.

10. Keadle SK, McKinnon R, Graubard BI, Troiano RP. Prevalence and trends in physical activity among older adults in the United States: a comparison across three national surveys. Prev Med. 2016; 89: 37-43.

11. Mayo Clinic Staff. Exercise helps ease arthritis pain and stiffness. Mayo Clinic Web site. https://www.mayoclinic.org/diseasesconditions/arthritis/in-depth/arthritis/art-20047971. Accessed 04/2020.

12. lijima H, Aoyama T, Fukutani N, et al. Psychological health is associated with knee pain and physical function in patients with knee osteoarthritis: an exploratory cross-sectional study. BMC Psychol. 2018;6(1):19. doi: 10.1186/s40359-018-0234-3.

13. Ziarko M, Siemiątkowska K, Sieński M, et al. Mental health and rheumatoid arthritis: toward understanding the emotional status of people with chronic disease. Biomed Res Int. 2019;2019: 1473925. doi: 10.1155/2019/1473925.

14. Stubbs B, Veronese N, Vancampfort D, et al. Lifetime selfreported arthritis is associated with elevated levels of mental health burden: a multi-national cross sectional study across 46 low- and middle-income countries. Sci Rep. 2017;7(1):7138. doi: 10.1038/s41598-017-07688-6.

15. Nerurkar L, Siebert S, McInnes IB, Cavanagh J. Rheumatoid arthritis and depression: an inflammatory perspective. Lancet Psychiatry. 2019;6(2):164-173. doi: 10.1016/S2215-0366(18) 30255-4.

16. Euesden J, Matcham F, Hotopf M, et al. The relationship between mental health, disease severity, and genetic risk for depression in early rheumatoid arthritis. Psychosom Med. 2017;79(6): 638-645. doi: 10.1097/PSY.0000000000000462.
17. Chang K, Yang SM, Kim SH, et al. Smoking and rheumatoid arthritis. Int J Mol Sci. 2014;15(12):22279-22295. doi: 10.3390/ ijms151222279.

18. Hootman JM, Macera CA, Ham SA, et al. Physical activity levels among the general US adult population and in adults with and without arthritis. Arthritis Rheum. 2003;49(1):129-135. doi: 10. 1002/art.10911.

19. Shih M, Hootman JM, Kruger J, Helmick CG. Physical activity in men and women with arthritis National Health Interview Survey, 2002. Am J Prev Med. 2006;30(5):385-393. doi: 10.1016/j. amepre.2005.12.005.

20. Liu X, Tedeschi SK, Lu B, et al. Long-term physical activity and subsequent risk for rheumatoid arthritis among women: a prospective cohort study. Arthritis Rheumatol. 2019;71(9): 1460-1471. doi: 10.1002/art.40899.

21. Azeez M, Clancy C, O'Dwyer T, et al. Benefits of exercise in patients with rheumatoid arthritis: a randomized controlled trial of a patient-specific exercise programme. Clin Rheumatol. 2020; 39(6):1783-1792. doi: 10.1007/s10067-020-04937-4.

22. Sugiyama D, Nishimura K, Tamaki K, Tsuji G, Nakazawa T, Morinobu A, Kumagai S. Impact of smoking as a risk factor for developing rheumatoid arthritis: a meta-analysis of observational studies. Ann Rheum Dis. 2010;69(01):70-81.

23. Price JD, Barbour KE, Liu Y, et al. State-specific prevalence and characteristics of frequent mental distress and history of depression diagnosis among adults with arthritis - United States, 2017. MMWR Morbidity and Mortality Weekly Report. 2020;68(5152):1173-1178. doi: 10.15585/mmwr.mm685152a1.

24. Brooks JM, Titus AJ, Polenick CA, et al. Prevalence rates of arthritis among US older adults with varying degrees of depression: findings from the 2011 to 2014 National Health and Nutrition Examination Survey. Int J Geriatr Psychiatry. 2018;33(12): 1671-1679. doi: 10.1002/gps.4971.

25. Oesterle S, Hill KG, Hawkins JD, et al. Adolescent heavy episodic drinking trajectories and health in young adulthood. JStud Alcohol. 2004;65(2):204-212. doi: 10.15288/jsad.2004.65.204. 